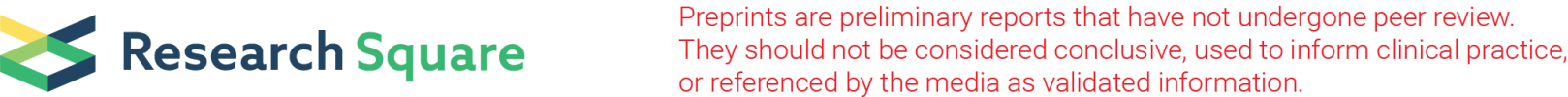

\section{A Cost-Effectiveness Analysis of Neoadjuvant Therapy for Neuroendocrine Cervical Tumors}

\section{Yingtao Lin}

Fujian Medical University Cancer Hospital, Fujian Cancer Hospital https://orcid.org/0000-0001-91680491

\section{Ying Chen}

Fujian Medical University Cancer Hospital, Fujian Cancer Hospital

Haixin He

Fujian Medical University Cancer Hospital, Fujian Cancer Hospital

Jian Chen ( $\sim$ Marsz3@126.com )

https://orcid.org/0000-0003-4234-2028

\section{Research}

Keywords: Cost-effectiveness, Neoadjuvant therapy, Neuroendocrine cervical tumors, Radical surgery, Uterine cervix

Posted Date: November 9th, 2021

DOI: https://doi.org/10.21203/rs.3.rs-1032996/v1

License: (c) (i) This work is licensed under a Creative Commons Attribution 4.0 International License. Read Full License 


\section{Abstract}

Purpose. This study aimed to assess the cost-effectiveness of neoadjuvant therapy in combination with surgery and adjuvant therapy compared with either surgery alone or surgery plus adjuvant therapy for the treatment of neuroendocrine cervical tumors (NETs).

Materials and methods. A single-institution retrospective analysis of 107 patients with NETs was performed based on the new International Federation of Gynecology and Obstetrics (FIGO 2018) staging system. We divided the patients who underwent radical surgery into two groups: neoadjuvant therapy (NACT) and non-neoadjuvant therapy (non-NACT) groups. We performed subgroup analysis of overall survival and cost-effectiveness by dividing the patients with stage I-IV disease into four subgroups. An assessment was constructed to reflect the costs and effectiveness of the treatment from the perspectives of both clinical practice and health economics.

Results. The NACT group had -0.45 life-years (LYs) at an incremental cost of $\$ 15197.58$, compared with the non-NACT group, which means that it is not cost-effective. However, subgroup analysis of patients with stage II disease showed that the NACT group had significantly better overall survival time than the non-NACT group (median overall survival had not been reached versus 29.23 months, $p \otimes 0.001$ ). The NACT group had an incremental cost-effectiveness ratio (ICER) of $\$ 5921.43 /$ LY compared with the nonNACT group for stage II disease. Probabilistic sensitivity analyses showed that when the willingness-topay (WTP) threshold reached $\$ 31118.29 /$ LY, which is nearly three times China's per capita GDP 2020 , the probability of NACT being cost-effective was $97 \%$ versus non-NACT group in the treatment of stage II neuroendocrine tumors of the uterine cervix.

Conclusion. NACT is not a cost-effective treatment strategy compared with non-NACT in the treatment of NETs, but may be a cost-effective treatment option for stage II NETs.

\section{Background}

Uterine cervical cancer is the fourth most common cancer in women worldwide with neuroendocrine cervical tumors (NETs) representing a rare and highly aggressive subgroup.[1-3] According to the World Health Organization (WHO), there are four categories of NETs: small cell carcinoma, large cell neuroendocrine carcinomas, typical carcinoid tumors, and atypical carcinoid tumors.[4] Small cell carcinoma is the most common NET, but still only accounts for less than $5 \%$ of all cervical carcinomas.[5] Some studies have retrospectively summarized data on the treatment of NETs, but most of them lacked large samples, because of the rarity of NETs.[6,7] Therefore, there is no global consensus on the optimal treatment for NETs. Radical surgery is usually administered for early stage disease, concurrent chemoradiotherapy for locally advanced disease, and chemotherapy for metastatic and recurrent disease.[2] The use of neoadjuvant therapy (NACT) to treat NETs remains controversial. Some authors have proposed the use of NACT because it can lead to complete tumor response[8, 9]. In contrast, others 
reported no benefit in overall survival among patients who received NACT [10]. It is difficult to draw a definitive conclusion because of the small sample sizes. However, the cost increase associated with NACT. The high price of NACT agents imposes the heavy economic burdens on women. It is important to assess the economic impact of NACT options on both patients and healthcare systems to ensure that resources are used efficiently[11], especially in China, a country with limited resources. If shown to be cost-effective, women's health rights and interests can be better protected[12, 13]. We performed a retrospective review of 107 patients to evaluate the cost-effectiveness of the NACT options by quantifying and comparing the therapy's cost and effectiveness from the perspective of Chinese society, and to support appropriate treatment advice for women with NETs.

\section{Methods}

\section{Target population}

In this study, the target population was treated at the Department of Gynecology at Fujian Cancer Hospital between 2002 and 2019. The inclusion criteria were patients at least 18 years of age (range, 2586 years) with a histologically confirmed diagnosis of NETs from two specialized pathologists and who had undergone radical surgery. Patients with incorrect pathology reports or who lacked follow-up data were excluded.

\section{Study construction}

We constructed a cost and effectiveness assessment of NACT versus non-neoadjuvant therapy. This assessment method has previously been established for other forms of cancer treatment and has also been used to estimate health outcomes and costs for each regimen in specified patient populations.[1416]

\section{Cost}

In this study, the cost assessment was mainly based on hospitalization expenses including surgery, nursing, laboratory tests and scans, drug acquisition and administration, and other treatment costs which occurred during hospitalization. All costs were taken from the medical expenses of Fujian Medical University Cancer Hospital, and the prices were published by the Fujian Provincial Health Commission. The exchange rate to USD was calculated on June 2020.

\section{Outcomes}

Because there is no literature or studies on the utility scores related to quality-adjusted life years (QALYs) for NETs, we chose life-years (LYs) instead of QALYs as our primary outcome.[17, 18] Cost and effectiveness were evaluated from the payer's perspective using the variable incremental costeffectiveness ratio (ICER). The ICER is a numerical value indicating how much it would cost to gain a unit of LYs.[19]

\section{Discount rate}


According to the Second Edition of Cost-Effectiveness in Health and Medicine,[20] costs had a discounted rate of $3 \%$ per year.

\section{Sensitivity analyses}

A deterministic sensitivity analysis took all the input variables of the study and change them by $20 \%$ in both directions. When one input variable was changed, the others were kept constant. Probabilistic sensitivity analysis was performed using a Monte Carlo simulation. One thousand simulation iterations were run, and the values for both groups were sampled at random from the normal distribution based on the study sample means and their standard deviation.

\section{Statistical analysis}

Statistical analysis was conducted using Tree Age Pro 2011, Excel 2019, and SPSS 26.0. Tree Age Pro 2011 was used to establish the study structure. Excel was used to calculate the cost and outcome, as well as conduct the deterministic sensitivity and probabilistic sensitivity analyses. SPSS was used for survival analysis. The median overall survival of the NACT group, non-NACT group, and subgroups were estimated using the Kaplan-Meier method. Time-to-event endpoints were compared between subgroups using the log-rank test stratified by the randomization strata.

\section{Results}

\section{Base-case analysis}

A total of 107 eligible patients were enrolled, including 69 and 38 patients in the NACT and non-NACT groups, respectively. Informed consent was not required because of the retrospective nature of this study. The characteristics of the 107 enrolled patients at the start of the study were used as baseline data (Table 1). And, we constructed the cost and effectiveness assessment of NACT versus non-NACT (Fig. 1). 
Table 1

The characteristics of patients ( $\mathrm{N}=107)$

\begin{tabular}{|c|c|c|c|c|}
\hline Characteristics & $\begin{array}{l}\text { NACT } \\
\text { group } \\
(n=69)\end{array}$ & $\begin{array}{l}\text { NACT } \\
\text { group } \\
(\%)\end{array}$ & $\begin{array}{l}\text { non-NACT } \\
\text { group } \\
(n=38)\end{array}$ & $\begin{array}{l}\text { non-NACT } \\
\text { group } \\
(\%)\end{array}$ \\
\hline \multicolumn{5}{|l|}{ Age } \\
\hline Median, years & 44 & & 43 & \\
\hline \multicolumn{5}{|l|}{ Histological classification } \\
\hline Typical carcinoid tumors & 2 & $2.90 \%$ & 0 & $0.00 \%$ \\
\hline Atypical carcinoid tumors & 0 & $0.00 \%$ & 0 & $0.00 \%$ \\
\hline $\begin{array}{l}\text { Large cell neuroendocrine } \\
\text { carcinomas }\end{array}$ & 5 & $7.25 \%$ & 0 & $0.00 \%$ \\
\hline Small cell carcinomas & 62 & $89.86 \%$ & 37 & $97.37 \%$ \\
\hline Not classified & 0 & $0.00 \%$ & 1 & $2.63 \%$ \\
\hline \multicolumn{5}{|c|}{ Subgroups (Stage, FIGO 2018) } \\
\hline I & 4 & $5.80 \%$ & 25 & $65.79 \%$ \\
\hline II & 42 & $60.87 \%$ & 7 & $18.42 \%$ \\
\hline III & 23 & $33.33 \%$ & 6 & $15.79 \%$ \\
\hline IV & 0 & $0.00 \%$ & 0 & $0.00 \%$ \\
\hline \multicolumn{5}{|l|}{ Chemotherapy regimen } \\
\hline TP & 37 & $53.62 \%$ & 12 & $31.58 \%$ \\
\hline EP & 27 & $39.13 \%$ & 21 & $55.26 \%$ \\
\hline Others & 5 & $7.25 \%$ & 3 & $7.89 \%$ \\
\hline
\end{tabular}

Our data cutoff date was June 7, 2020. At that time, 33 (47.14\%) deaths occurred in the NACT group and $14(36.84 \%)$ in the non-NACT group. The median overall survival was 75.80 months in the NACT group compared with 81.27 months in the non-NACT group (Fig. 2).

These statistical results were converted to LYs for the outcome calculation. LYs in the NACT group were associated with an expected gain of $6.32 \mathrm{LYs}$, while the non-NACT group had an expected gain of 6.77 LYs. The total mean cost for the NACT group was $\$ 32424.51$ per patient, while the cost for the non-NACT group was $\$ 17952.18$. The NACT group gained an incremental cost and effect of $\$ 14472.33$ and -0.45 LYs compared with the non-NACT group (Table 2). 
Table 2

Key outcome data of the NACT versus non-NACT

\begin{tabular}{|c|c|c|c|c|}
\hline $\begin{array}{l}\text { Outcome } \\
\text { results }\end{array}$ & $\begin{array}{l}\text { NACT group in all } \\
\text { patients }\end{array}$ & $\begin{array}{l}\text { non-NACT group in all } \\
\text { patients }\end{array}$ & $\begin{array}{l}\text { NACT group } \\
\text { in the stage II } \\
\text { disease }\end{array}$ & $\begin{array}{l}\text { non-NACT } \\
\text { group } \\
\text { in the stage II } \\
\text { disease }\end{array}$ \\
\hline \multicolumn{5}{|l|}{ Cost } \\
\hline $\begin{array}{l}\text { Total } \\
\text { costs/patient }\end{array}$ & $\$ 32424.51$ & $\$ 17,952.18$ & $\$ 33,469.07$ & $\$ 12,388.77$ \\
\hline \multicolumn{5}{|l|}{ Effectiveness } \\
\hline LYs & 6.32 & 6.77 & 6.00 & 2.44 \\
\hline \multicolumn{5}{|l|}{ ICER } \\
\hline$\$ / L Y s$ & NA & & $\$ 5,921.43$ & \\
\hline
\end{tabular}

\section{Subgroup analysis}

To assess the effect of treatment, the patients were divided into four subgroups based on the FIGO 2018 staging system[21]. Of the patients in the NACT group, four were classified as having stage I disease, 42 had stage II disease, 23 had stage III disease, and zero had stage IV disease. Meanwhile, in the Non-NACT group, 25 had stage I disease, seven had stage II disease, six had stage III disease, and zero had stage IV disease. Subgroup analysis showed that the survival benefits favored the NACT group over the non-NACT group in patients with stage II disease (Fig. 3). There were 16 (61.90\%) deaths that occurred in the NACT group and five (71.43\%) in the non-NACT group. The NACT group had a significantly better overall survival time (median overall survival was not reached versus 29.23 months, $p \otimes 0.001$ ) in patients with stage II disease.

Due to the improved overall survival in the NACT group of patients with stage II disease, we used 72.03 months (53.7\% overall survival rate) for outcome calculation. Lys were also used for this outcome calculation. Of the patients with stage II disease, the NACT group had an expected gain of $6.00 \mathrm{LYs}$ versus $2.44 \mathrm{LYs}$ gained in the non-NACT group. The total mean cost of the NACT group was $\$ 33469.07$ per patient, compared to $\$ 12388.77$ in the non-NACT group. The NACT group gained an incremental cost and effect of $\$ 21080.30$ and 3.56 LYs compared with the non-NACT group (Table 2).

\section{Sensitivity analyses}

\section{Deterministic sensitivity analyses}


The one-way deterministic sensitivity analyses of stage II patients showed that the life-years of the NACT group were the most sensitive to the model. The cost of the NACT group also had a strong influence on the model's results (Fig. 4).

\section{Probabilistic sensitivity analyses}

The Monte Carlo probabilistic sensitivity analyses of patients with stage II disease showed that the NACT group had a $53 \%$ probability of being cost-effective at a WTP threshold of $\$ 5921.43 /$ LY. If the WTP threshold reached a value of $\$ 31118.29 / \mathrm{LY}$, which is nearly three times China's per capita GDP 2020, the probability of NACT group being cost-effective was $97 \%$ (Fig. $5 \& 6$ ).

\section{Discussion}

To the best of our knowledge, this study is the largest health economics research study of NETs and also one of the largest single-center studies of NETs. It is worth noting that in recent years, healthcare-related costs have become a severe worldwide problem.[22-24] From a health economic evaluation perspective, in order for a treatment strategy to be cost-effective, it must have two key points: less cost and more effectiveness[25], which in our study were determined by less incremental cost and more incremental LYs. It has been reported that, during NACT treatment and beyond, increases in treatment cycle, adverse events, and healthcare expenditures are inevitable because of decreased functioning and worsening symptoms[26, 27], which was consistent with our observations. The patients suffered from a double burden of physical pain and financial stress. In the base-case analysis, the NACT group gained both an incremental cost of $\$ 14472.33$ and incremental effect of $-0.45 \mathrm{LYs}$ compared with the non-NACT group. Thus, the first finding in our study is that NACT is not a cost-effective treatment strategy compared with non-NACT for NETs treatment.

NACT aims to shrink the mass and kill invisible metastatic cells early enough to facilitate subsequent treatments such as surgery and radiotherapy. This makes surgery possible for patients who would otherwise be considered inoperable or difficult to operate, thus providing a chance of eradicating the tumor to patients[28, 29]. In the subgroup analysis, NACT showed encouraging clinical efficacy in patients with stage II disease. In this subgroup, the survival benefits favored the NACT group over the non-NACT group. The patients with stage II disease in the NACT group had significantly improved median overall survival, a $53.7 \%$ overall survival rate at 72.03 months versus $0 \%$ overall survival rate in 37.13 months. A previous study by Intaraphet et al. reported that the overall survival rate in 5 years was $54 \%$ in patients stage IIA disease and $26 \%$ in those with stage IIB disease,[30] while another study by Zhou et al. found the overall survival rate in 5 years was $49.7 \%$ in patients with stage II disease.[31] Due to lymph node metastasis, 5 patients at stage I, 24 patients at stage II, were upstaged to stage IIIC according to FIGO 2018 staging system. We speculate that patients without involvement of the pelvic and/or paraaortic lymph nodes are more likely to benefit from neoadjuvant therapy. NACT is also a cost-effective treatment strategy compared to non-NACT for stage II neuroendocrine tumors of the uterine cervix. The ICER for the NACT group compared to the non-NACT group was $\$ 5921.43 /$ LY for patients with stage II 
disease. The Monte Carlo probabilistic sensitivity analysis of the stage II disease showed that, when using the $\$ 5921.43 /$ LY as the WTP threshold, the NACT group had a 53\% probability of being costeffective compared with the non-NACT group. According to the WHO the WTP threshold should be of three times the GDP per capita for China,[32] which was $\$ 31512 / L Y$ in 2020. When the WTP threshold had an ICER value of $\$ 31118.29 / \mathrm{LY}$, the NACT group had a $97 \%$ probability of becoming an advantageous option compared to the non-NACT group. Both ICER values were lower than the WHO threshold, which supports the use of NACT as a more cost-effective treatment option than non-NACT treatment options for stage II neuroendocrine tumors of the uterine cervix.

Furthermore, in the one-way sensitivity analyses of stage II disease, the most influential variable in the NACT group was the life-years (converted from the median survival time), in which a longer survival time would result in higher treatment costs but also be more cost-effective. To our knowledge, there have been no cost-effective studies of NETs, but a few studies have reported cost-effectiveness in carcinoma of the cervix. It has been reported that gemcitabine with cisplatin chemoradiation followed by two cycles of adjuvant gemcitabine and cisplatin had a high treatment cost beyond the WTP threshold for locally advanced cervical cancer compared to standard cisplatin chemoradiation, which leads to less costeffectiveness.[19] Standard doublet chemotherapy is also not a cost-effective treatment option compared to selective chemotherapy in recurrent cervical cancer.[16] Further, the cost of chemotherapy in combination with bevacizumab was not a cost-effective treatment option compared to chemotherapy.[33, 34] Survival time had a significant influence in these studies. The treatment arm gained the overall survival advantage while simultaneously receiving an exorbitant cost. Thus, to improve the economic effectiveness of neuroendocrine cervical tumor treatment, it is essential to identify the most suitable patients with the best survival benefits and determine the financial feasibility for NACT in combination with surgery plus adjuvant therapy.

It should be acknowledged that our analyses has several strengths and limitations. The major strengths are the large sample size, specific follow-up data, and complete hospitalization expenses for rare neuroendocrine tumors of the uterine cervix. Additionally, the results of our study have clinical and economic benefits from both medical and health economic perspectives. Furthermore, the cost and effectiveness variables are based on the medical course rather than those found in references. This study also has some limitations. First, by using LYs instead of QALYs, the results may have a bias towards quality of life. Second, hospitalization expenses are total costs and were not divided by category. Third, our study is a single-institution study, which might undermine the robustness of the economic evaluation.

\section{Conclusions}

In conclusion, NATC is not a cost-effective treatment strategy compared with non-NACT in the treatment of NETs but is a cost-effective strategy in the treatment of stage II neuroendocrine tumors of the uterine cervix. Patients can gain both survival and financial benefits in stage II disease by treatment with NACT.

\section{Declarations}


Ethics approval and consent to participate

The study for investigations involving human subjects and informed consent was obtained from the Ethics Committee of Fujian Cancer Hospital.

Consent for publication

Not applicable.

Availability of data and materials

The datasets used and/or analysed during the current study are available from the corresponding author on reasonable request.

Competing interests

The authors declare that they have no competing interests.

\section{Funding}

This study supported by the Startup Fund for Scientific Research, Fujian Medical University (Grant number: 2019QH1201) and (Grant number: 2020QH1216).

\section{Authors' contributions}

All authors participated in the design of the study. Ying-Tao Lin and Jian Chen analyzed the data and drafted the manuscript. Ying Chen and Hai-Xin He reviewed the drafts of the manuscript. All authors read and approved the final manuscript.

\section{Acknowledgements}

Not applicable.

\section{References}

1. Burzawa J, Gonzales N, Frumovitz M. Challenges in the diagnosis and management of cervical neuroendocrine carcinoma. Expert Rev Anticancer Ther. 2015;15(7):805-10. doi: 10.1586/14737140.2015.1047767.

2. Satoh T, Takei Y, Treilleux I, Devouassoux-Shisheboran M, Ledermann J, Viswanathan AN, et al. Gynecologic Cancer InterGroup (GCIG) consensus review for small cell carcinoma of the cervix. Int J Gynecol Cancer. 2014;24(9 Suppl 3):S102-8. doi: 10.1097/IGC.0000000000000262.

3. Gardner GJ, Reidy-Lagunes D, Gehrig PA. Neuroendocrine tumors of the gynecologic tract: A Society of Gynecologic Oncology (SGO) clinical document. Gynecol Oncol. 2011;122(1):190-8. doi: 10.1016/j.ygyno.2011.04.011. 
4. Albores-Saavedra J, Gersell D, Gilks CB, Henson DE, Lindberg G, Santiago H, et al. Terminology of endocrine tumors of the uterine cervix: results of a workshop sponsored by the College of American Pathologists and the National Cancer Institute. Arch Pathol Lab Med. 1997;121(1):34-9.

5. Viswanathan AN, Deavers MT, Jhingran A, Ramirez PT, Levenback C, Eifel PJ. Small cell neuroendocrine carcinoma of the cervix: outcome and patterns of recurrence. Gynecol Oncol. 2004;93(1):27-33. doi: 10.1016/j.ygyno.2003.12.027.

6. Zivanovic O, Leitao MM, Jr., Park KJ, Zhao H, Diaz JP, Konner J, et al. Small cell neuroendocrine carcinoma of the cervix: Analysis of outcome, recurrence pattern and the impact of platinum-based combination chemotherapy. Gynecol Oncol. 2009;112(3):590-3. doi: 10.1016/j.ygyno.2008.11.010.

7. Hoskins PJ, Swenerton KD, Pike JA, Lim P, Aquino-Parsons C, Wong F, et al. Small-cell carcinoma of the cervix: fourteen years of experience at a single institution using a combined-modality regimen of involved-field irradiation and platinum-based combination chemotherapy. J Clin Oncol. 2003;21(18):3495-501. doi: 10.1200/JC0.2003.01.501.

8. Chang TC, Hsueh S, Lai CH, Tseng CJ, Lee KF, Huang KG, et al. Phase II trial of neoadjuvant chemotherapy in early-stage small cell cervical cancer. Anticancer Drugs. 1999;10(7):641-6. doi: 10.1097/00001813-199908000-00003.

9. Bermudez A, Vighi S, Garcia A, Sardi J. Neuroendocrine cervical carcinoma: a diagnostic and therapeutic challenge. Gynecol Oncol. 2001;82(1):32-9. doi: 10.1006/gyno.2001.6201.

10. Lee JM, Lee KB, Nam JH, Ryu SY, Bae DS, Park JT, et al. Prognostic factors in FIGO stage IB-IIA small cell neuroendocrine carcinoma of the uterine cervix treated surgically: results of a multi-center retrospective Korean study. Ann Oncol. 2008;19(2):321-6. doi: 10.1093/annonc/mdm465.

11. Woolf SH. Potential health and economic consequences of misplaced priorities. JAMA. 2007;297(5):523-6. doi: 10.1001/jama.297.5.523.

12. Ramsey SD, Ganz PA, Shankaran V, Peppercorn J, Emanuel E. Addressing the American health-care cost crisis: role of the oncology community. J Natl Cancer Inst. 2013;105(23):1777-81. doi: 10.1093/jnci/djt293.

13. McGlynn EA, Asch SM, Adams J, Keesey J, Hicks J, DeCristofaro A, et al. The quality of health care delivered to adults in the United States. N Engl J Med. 2003;348(26):2635-45. doi: 10.1056/NEJMsa022615.

14. Insinga RP, Vanness DJ, Feliciano JL, Vandormael K, Traore S, Burke T. Cost-effectiveness of pembrolizumab in combination with chemotherapy in the 1 st line treatment of non-squamous NSCLC in the US. J Med Econ. 2018;21(12):1191-205. doi: 10.1080/13696998.2018.1521416.

15. Chouaid C, Bensimon L, Clay E, Millier A, Levy-Bachelot L, Huang M, et al. Cost-effectiveness analysis of pembrolizumab versus standard-of-care chemotherapy for first-line treatment of PD-L1 positive $(>50 \%)$ metastatic squamous and non-squamous non-small cell lung cancer in France. Lung Cancer. 2019;127:44-52. doi: 10.1016/j.lungcan.2018.11.008.

16. Phippen NT, Leath CA, 3rd, Miller CR, Lowery WJ, Havrilesky LJ, Barnett JC. Are supportive care-based treatment strategies preferable to standard chemotherapy in recurrent cervical cancer? Gynecol 
Oncol. 2013;130(2):317-22. doi: 10.1016/j.ygyno.2013.05.019.

17. Lin CY, Fang HY, Feng CL, Li CC, Chien CR. Cost-effectiveness of neoadjuvant concurrent chemoradiotherapy versus esophagectomy for locally advanced esophageal squamous cell carcinoma: A population-based matched case-control study. Thorac Cancer. 2016;7(3):288-95. doi: 10.1111/1759-7714.12326.

18. Cohn DE, Kim KH, Resnick KE, O'Malley DM, Straughn JM, Jr. At what cost does a potential survival advantage of bevacizumab make sense for the primary treatment of ovarian cancer? A costeffectiveness analysis. J Clin Oncol. 2011;29(10):1247-51. doi: 10.1200/JC0.2010.32.1075.

19. Phippen NT, Leath CA, 3rd, Chino JP, Jewell EL, Havrilesky LJ, Barnett JC. Cost effectiveness of concurrent gemcitabine and cisplatin with radiation followed by adjuvant gemcitabine and cisplatin in patients with stages IIB to IVA carcinoma of the cervix. Gynecol Oncol. 2012;127(2):267-72. doi: 10.1016/j.ygyno.2012.08.002.

20. Nyman JA. Cost Recommendations in the Second Edition of Cost-Effectiveness in Health and Medicine: A Review. MDM Policy Pract. 2018;3(1):2381468318765162. doi:

$10.1177 / 2381468318765162$.

21. Ishikawa M, Kasamatsu T, Tsuda H, Fukunaga M, Sakamoto A, Kaku T, et al. A multi-center retrospective study of neuroendocrine tumors of the uterine cervix: Prognosis according to the new 2018 staging system, comparing outcomes for different chemotherapeutic regimens and histopathological subtypes. Gynecol Oncol. 2019;155(3):444-51. doi: 10.1016/j.ygyno.2019.09.018.

22. Global Burden of Disease Health Financing Collaborator N. Future and potential spending on health 2015-40: development assistance for health, and government, prepaid private, and out-of-pocket health spending in 184 countries. Lancet. 2017;389(10083):2005-30. doi: 10.1016/S01406736(17)30873-5.

23. Counts NZ, Taylor LA, Willison CE, Galea S. Healthcare lobbying on upstream social determinants of health in the US. Prev Med. 2021;153:106751. doi: 10.1016/j.ypmed.2021.106751.

24. Campolina AG. Value-based medicine in oncology: the importance of perspective in the emerging value frameworks. Clinics (Sao Paulo). 2018;73(suppl 1):e470s. doi: 10.6061/clinics/2018/e470s.

25. Woolf SH, Johnson RE. The break-even point: when medical advances are less important than improving the fidelity with which they are delivered. Ann Fam Med. 2005;3(6):545-52. doi: 10.1370/afm.406.

26. Wang KL, Chang TC, Jung SM, Chen $\mathrm{CH}$, Cheng YM, Wu HH, et al. Primary treatment and prognostic factors of small cell neuroendocrine carcinoma of the uterine cervix: a Taiwanese Gynecologic Oncology Group study. Eur J Cancer. 2012;48(10):1484-94. doi: 10.1016/j.ejca.2011.12.014.

27. Liao LM, Zhang X, Ren YF, Sun XY, Di N, Zhou N, et al. Chromogranin A (CgA) as poor prognostic factor in patients with small cell carcinoma of the cervix: results of a retrospective study of 293 patients. PLoS One. 2012;7(4):e33674. doi: 10.1371/journal.pone.0033674.

28. Caruso G, Palaia I, V DID, Pernazza A, Gallo R, Perniola G, et al. Radical Surgery After Neoadjuvant Chemotherapy for Locally Advanced Neuroendocrine Cancer of the Cervix. Anticancer Res. 
2021;41(9):4431-8. doi: 10.21873/anticanres.15250.

29. Bain E, Coleridge SL, Morrison J. Small cell neuroendocrine tumour of the cervix in pregnancy: the importance of multidisciplinary management. BMJ Case Rep. 2021;14(9). doi: 10.1136/bcr-2020237058.

30. Intaraphet S, Kasatpibal N, Siriaunkgul S, Chandacham A, Sukpan K, Patumanond J. Prognostic factors for small cell neuroendocrine carcinoma of the uterine cervix: an institutional experience. Int J Gynecol Cancer. 2014;24(2):272-9. doi: 10.1097/IGC.0000000000000059.

31. Zhou J, Yang HY, Wu SG, He ZY, Lin HX, Sun JY, et al. The local treatment modalities in FIGO stage I-II small-cell carcinoma of the cervix are determined by disease stage and lymph node status. Cancer Med. 2016;5(6):1108-15. doi: 10.1002/cam4.687.

32. Murray CJ, Evans DB, Acharya A, Baltussen RM. Development of WHO guidelines on generalized cost-effectiveness analysis. Health Econ. 2000;9(3):235-51. doi: 10.1002/(sici)10991050(200004)9:3<235::aid-hec502>3.0.co;2-o.

33. Phippen NT, Leath CA, 3rd, Havrilesky LJ, Barnett JC. Bevacizumab in recurrent, persistent, or advanced stage carcinoma of the cervix: is it cost-effective? Gynecol Oncol. 2015;136(1):43-7. doi: 10.1016/j.ygyno.2014.11.003.

34. Tewari KS, Sill MW, Long HJ, 3rd, Penson RT, Huang H, Ramondetta LM, et al. Improved survival with bevacizumab in advanced cervical cancer. N Engl J Med. 2014;370(8):734-43. doi: 10.1056/NEJMoa1309748.

\section{Figures}




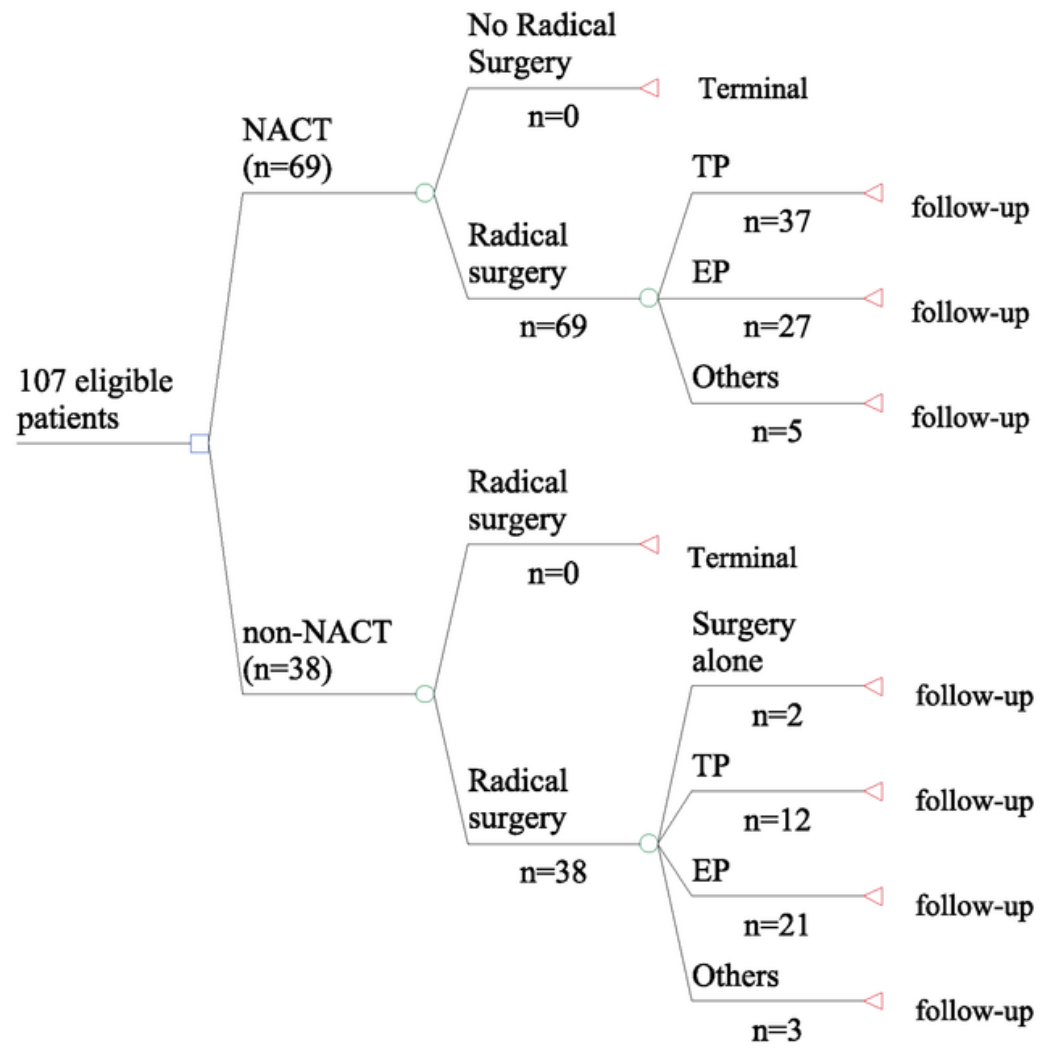

Figure 1

Study Construction

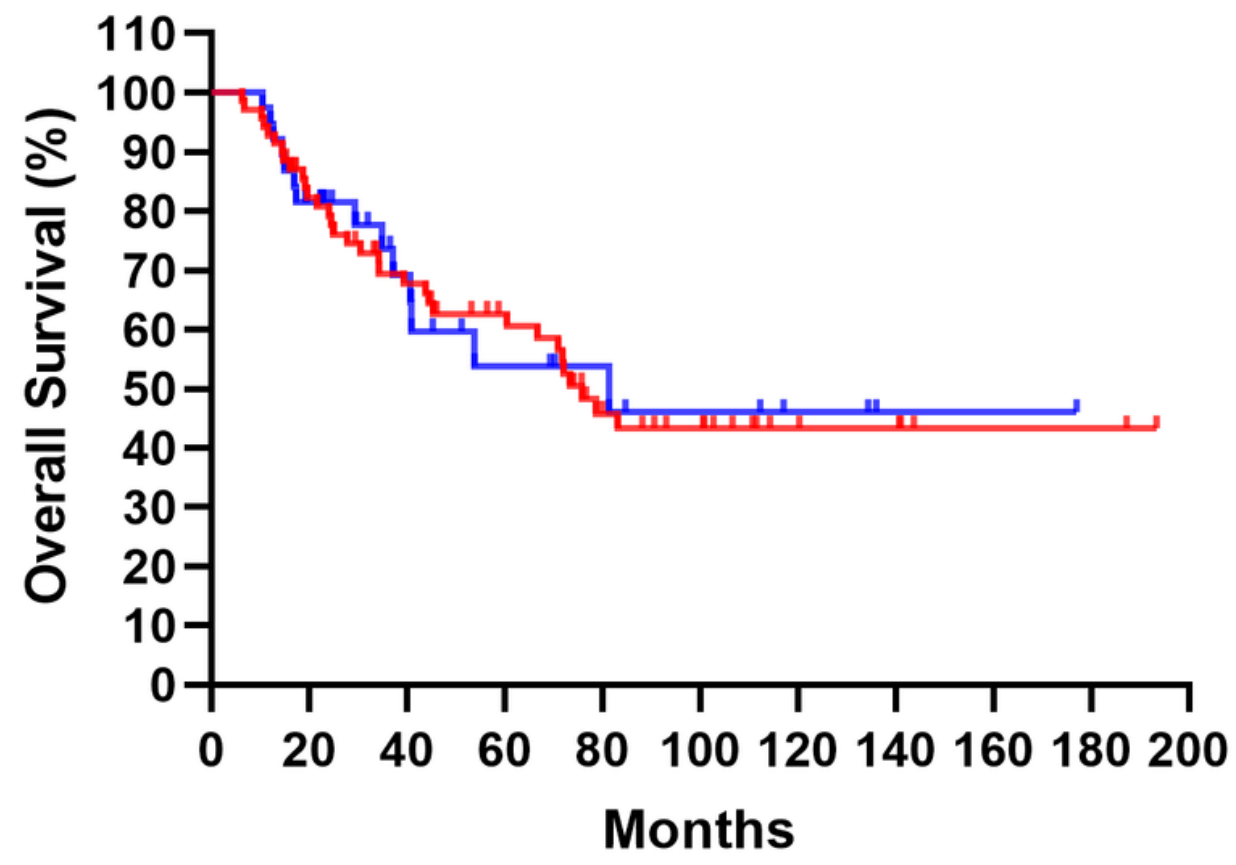

+ NACT group + non-NACT group 
Figure 2

Overall Survival Curve of NACT Group versus Non-NACT Group

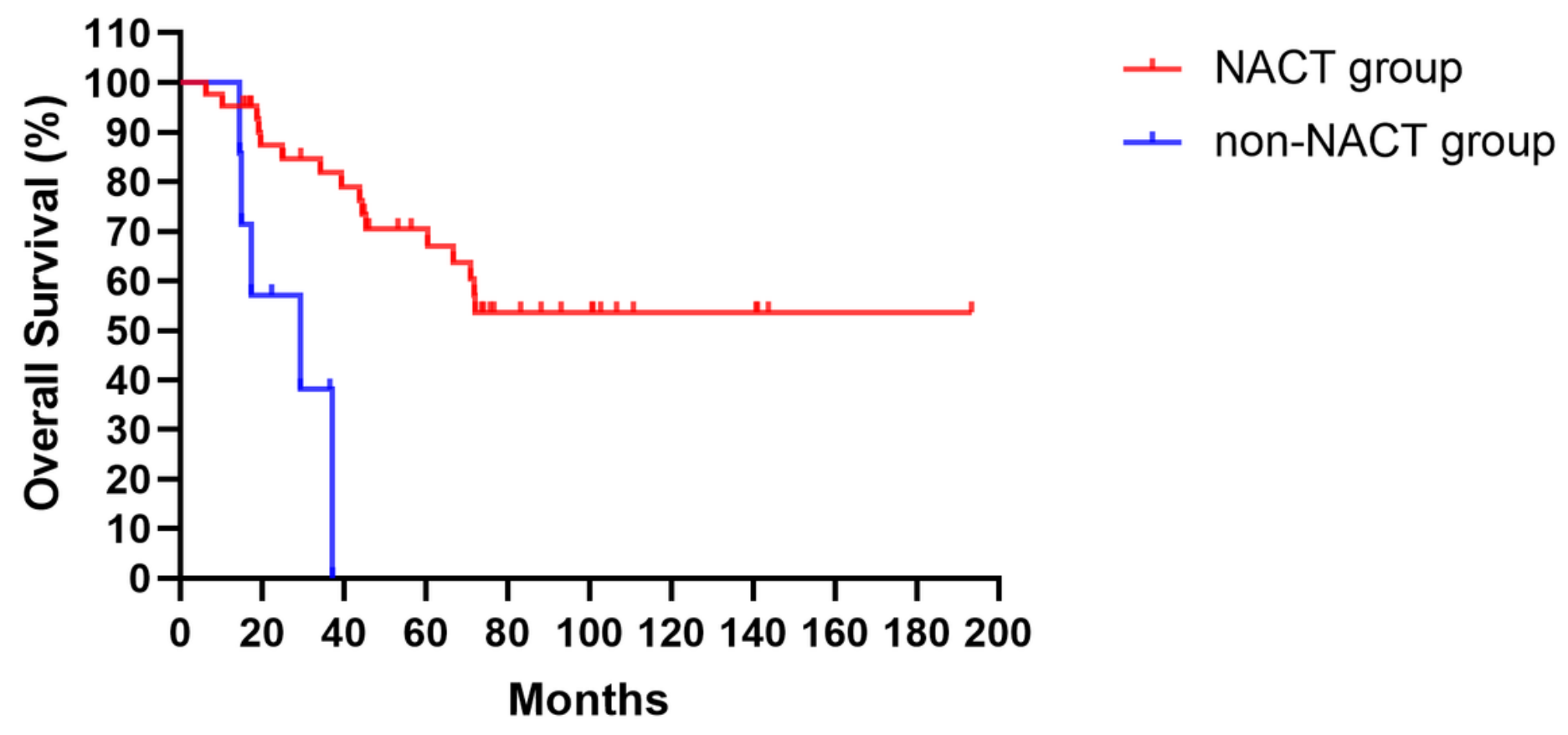

Figure 3

Overall Survival Curve of NACT Group versus Non-NACT Group in The Stage II Disease

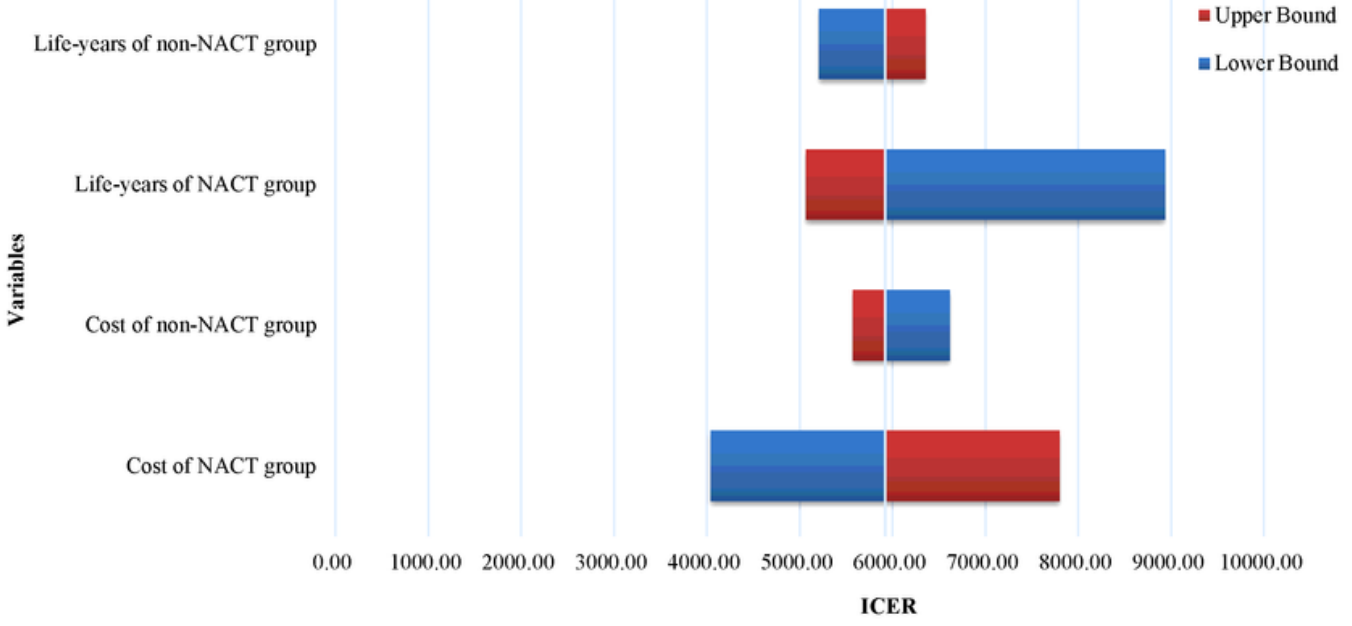

Figure 4 
Tornado Dagram for Deterministic Sensitivity Analyses of The ICER in The Stage II Disease

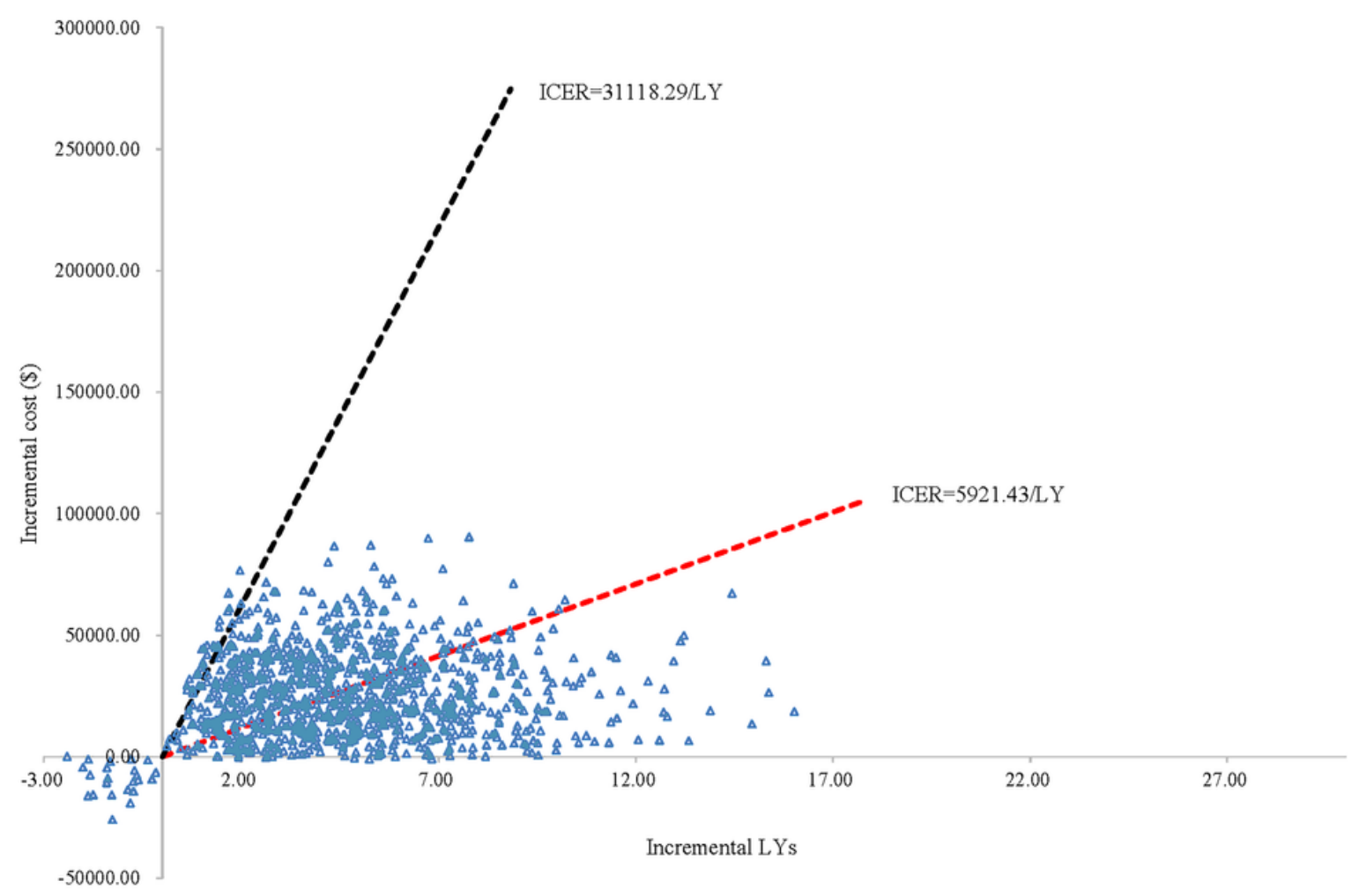

Figure 5

Scatter Plot of Monte Carlo Sensitivity Analysis 


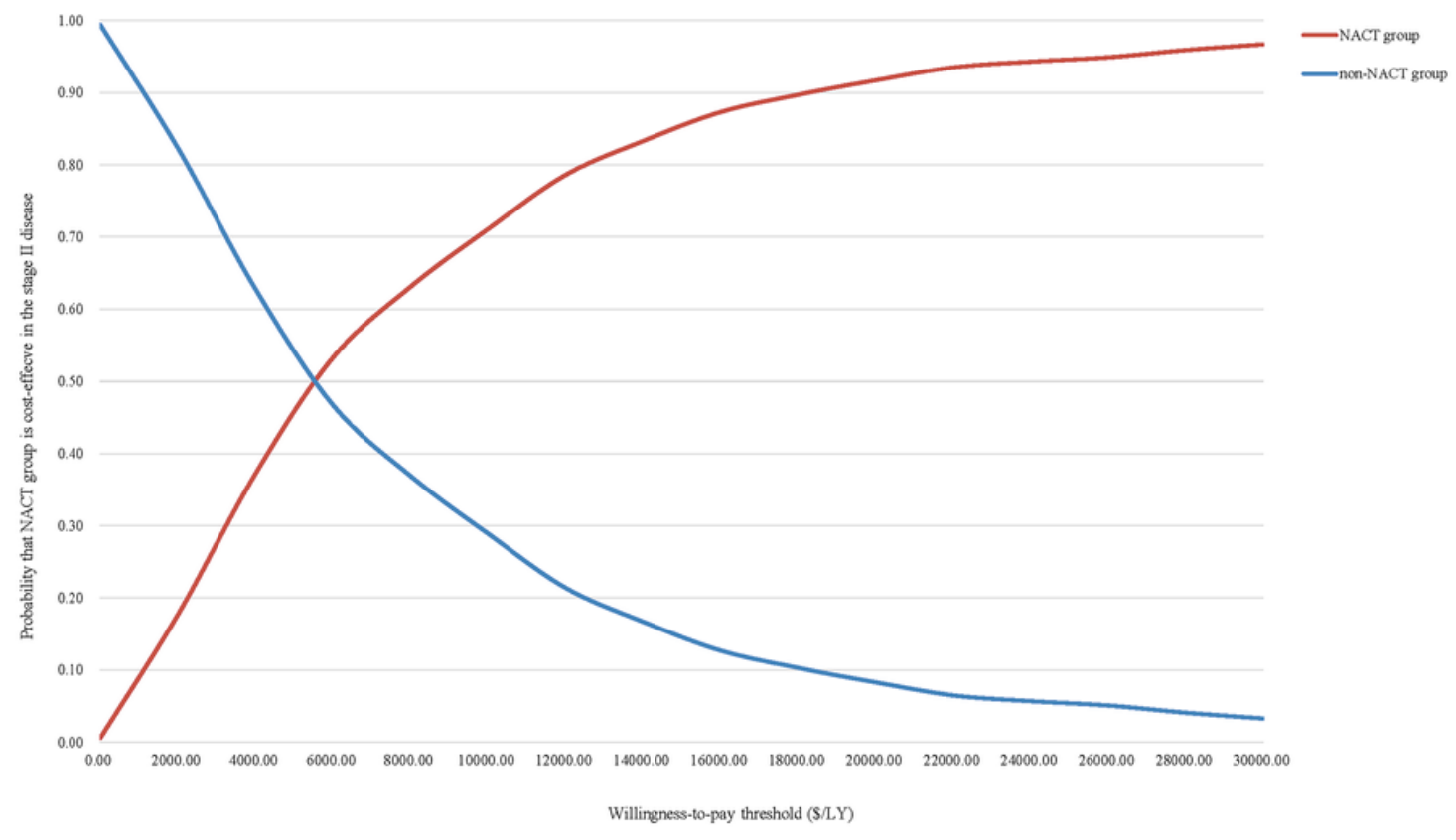

Figure 6

Cost-effectiveness Acceptability Curve for NACT group versus non-NACT group in The Stage II Disease

\section{Supplementary Files}

This is a list of supplementary files associated with this preprint. Click to download.

- supplementaryfiles1.xIsx

- supplementaryfiles2.xIsx 